\title{
El grito de la Gorgona: cristalización musical del mito
}

\section{The Gorgon's Shout: Musical Crystallization of Mythos}

\author{
Arturo García \\ Facultad de Bellas Artes, Universidad Michoacana de San Nicolás de Hidalgo. \\ Morelia, México. \\ artuchik@yahoo.com
}

\section{Resumen}

El artículo tiene como objeto la interrelación entre música y mito como modelo poiético en la antigua cultura griega. Su idea es mostrar cómo el mito da forma y contenido a la narración entonativa de acontecimientos en el nomos [vó $\mu$ oc], primera forma musical de la historia que surge de una estrecha relación entre la práctica musical y la mitología, expresada a través de la poesía arcaica y los certámenes musicales de Delfos. El título del artículo sintetiza la idea arquetípica de la antigüedad griega sobre el sentido de la armonía, la proporción, el límite y la medida, sobre la la cual se desarrolló su ideal artístico. El Grito de la Gorgona es pues una frase que acuña la descripción sonora de lo monstruoso, que los griegos expresaron con fantasía e imaginación en su música, dándole a este grito un orden y una forma de expresión artística.

Palabras clave: Aulo, Nomos, Entonación, Mito, Delfos, Gorgona.

\section{Abstract}

This article debates about the interrelation between the music and myth as a creative model in the archaic Greece. The idea is to show how the myth gives form and content to the narrative intonation of events in the nomos [vó $\mu \circ]$, the first musical form of history that emerge in a close relation between the musical practice and mythology, expressed throughout the archaic poetry and the musical contests in Delphos. The article's title synthetized the archetypical idea of the ancient Greek culture about the notion of harmony proportion and measurement in which the Greeks developed his artistic ideal. So, The Gorgon's shout is a phrase that coined the sonorous description of monstrosity that the ancient Greeks expressed whit fantasy in their music, giving to this shout an artistic order and form of expression.

Keywords: Aulos, Nomos, Intonation, Myth, Delphos, and Gorgon. 


\section{Mousiké}

Los más antiguos testimonios que existen sobre la música griega se encuentran en su mitología, relacionados evidentemente con el origen del mundo y el nacimiento de sus dioses. Al igual que otras culturas, con intuición e imaginación, el pueblo griego dio una explicación fantástica del mundo a través del mito. No obstante, a pesar de que estas historias están colmadas de situaciones fantásticas, los griegos rara vez se enfocaron en la descripción de lo monstruoso, característico de otros pueblos, revelando en su mitología el sentido de la armonía y la proporción, del límite y la medida, que posteriormente la filosofía griega elevara a rango de principio ontológico.

En estas narraciones simbólicas, relatadas en forma mítico-poética, los pueblos de la antigua Grecia expresaron sus ideas sobre el poder sobrenatural o terapéuticoreligioso de la música, que revelaba su origen divino. Es por ello que, a través de deidades y personajes míticos como Atenea, Apolo, Hermes, Dioniso, Pan y Marsias, los griegos vincularon la música a la poesía en íntima relación con el culto, la medicina o la teúrgia. Esta relación estuvo reflejada incluso en la palabra misma que designó por

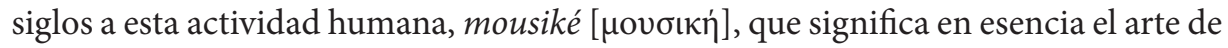
la memoria o inspiración de las Musas (García).

La mitología griega posee múltiples leyendas sobre dioses relacionados con la música, ya que el mito fue el medio a través del cual el pueblo griego expresó sus concepciones musicales. En ellas los dioses ejercen su poder a través de la música, creando los instrumentos musicales que les sirven de interacción con el hombre y la naturaleza, así como entre ellos mismos.

Dichas historias fueron narradas por el aedo [ảotઈóc], poeta arcaico que en su canto describía de manera simbólica el mundo. Pero el poeta no solo se limitó a narrar una serie de hechos, sino que ofrecía también sus causas y sus razones a un nivel mítico-fantástico. Esta manera poética de contemplar las razones de las cosas allanará el camino en la búsqueda de las causas, del principio y del porqué último del mundo en la filosofía. Pero su búsqueda fue primero a través de la divinización del mundo y la personificación de los fenómenos naturales y actividades cotidianas del hombre, como la música; el arte que mejor expresa la alegría y el dolor de la vida humana.

La música era para los griegos de inspiración divina y, por lo tanto, no se le consideraba un arte, es decir, una habilidad o destreza, sino un don otorgado por las Musas. El término ars, que es el equivalente latino del término griego techné [ $\tau \dot{\chi} \chi \vee \eta]$, significa destreza, es decir, la habilidad requerida para construir un objeto. El arte, tal y como se entendía en la antigüedad, tenía un ámbito considerablemente más amplio que el concepto moderno, y comprendía, además de las "bellas artes", los oficios manuales y las ciencias. Es más, se consideraba que el arte no solo era el producto de la destreza, sino la destreza misma, esto es, el dominio de las reglas y el conocimiento del experto en alguna ciencia. Es por ello que en el periodo clásico el 


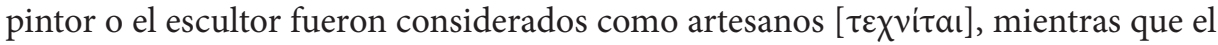
poeta era una especie profeta, encargado de trasmitir el designio divino (Tatarkiewicz, Historia de seis ideas; Historia de la estética).

La poesía para los griegos constituía un orden superior a las artes, y su inspiración solo podía provenir de los dioses. El poeta, animado por un espíritu divino, tenía una gran capacidad de influir en la vida espiritual de los hombres. Una capacidad irracional que fascinaba y seducía las mentes. Originalmente, la poesía griega se mantuvo en la dimensión de la oralidad, y era entonada con el acompañamiento de la lira, la forminge $e^{1}$ la cítara. En esta práctica musical, básicamente vocal en el periodo arcaico, los griegos asociaron la palabra con la melodía y ritmo instrumental en la ritmoentonación de los pies de la poesía épica y lírica. La poesía se cantaba. La música se vocalizaba. Ambas compartía la inspiración divina de las Musas, a diferencia de las artes basadas en la razón y habilidades manuales. Este era básicamente el concepto de la mousiké, de la poesía cantada, de la ritmo-entonación acompañada de la lira. Por ello filósofos como Platón o Aristóteles consideraron que la música tenía el poder de estimular y purificar, teniendo un significado moral y metafísico al igual que la poesía.

\section{Éthos}

Esta propiedad de la música, de expresar emociones e influir en el comportamiento

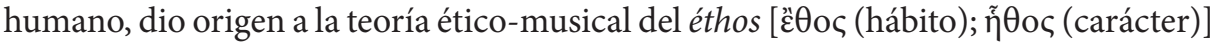
atribuida al músico presocrático Damon de Oda. ${ }^{2}$ La teoría afirma que el éthos es el principal atributo de la música, de allí proviene su gran valor educativo en tanto vehículo primordial entre el mundo de los sonidos y el ético. Cada armonía provoca en el espíritu un movimiento en consonancia, que imita un determinado modo de ser. Esta imitación se encuentra basada en el principio de que la tensión de las cuerdas de la lira encuentra su correspondencia con las tensiones del alma. En su tratado De musica, Arístides Quintiliano ${ }^{3}$ explica la teoría del éthos, atribuida a Damon:

En efecto, las armonías, como decía, se asemejan a los intervalos que en ellas predominan o a los sonidos que las determinan; y los sonidos, a su vez, a los

1 Forminge [gr. $\varphi$ ó $\rho \mu \gamma \xi$ ], antiguo instrumento de cuerda griego en forma de u con una gran caja de resonancia semicircular. Sus brazos eran rectos y paralelos que se extendían sobre la caja, sosteniendo un travesaño recto que mantenía sus cuatro cuerdas en tensión. Este era el yugo, que posiblemente se giraba con horquillas para sujetar las cuerdas. La forminge es el instrumento que se menciona en la Ilíada y la Odisea (Anderson, Ethos and Education 8).

2 Damon de Oda (ca.500 - ca.443 a.C.), conocido como Damon de Atenas, fue discípulo de Lamprocles, Agatocles, y del sofista Pródico. Fue instructor de música de Pericles y de Dracón de Atenas, el instructor de música de Platón. El pensamiento musical de Platón estuvo indudablemente marcado por su obra. A Damon se le atribuye la teoría del ethos, aunque se considera obra de los pitagóricos (Platón, Laques 180c-180d; Plutarco, De musica, 1136e3-f1 [c.16-17]); Anderson "The Importance", Ethos and Education; Tatarkiewicz. Historia de la estética 90).

3 Пepi Movбıкп̃ (lat. De musica libri tres) de Arístides Quintiliano, es un tratado del siglo II-III d.C. que ofrece una visión holística de la música griega hacia el final de la antigüedad pagana. Abarca la práctica musical y la doctrina ética de la música (teoría del éthos), así como cuestiones filosóficas relacionadas con la metafísica platónica. 
movimientos y las afecciones del alma. Que por medio de la semejanza los sonidos, incluso en la melodía continua, no sólo modelan un éthos inexistente, tanto en los niños como en los mayores, sino que también sacan a la luz el que tienen dentro, lo mostraban también los discípulos de Damon (23-9).

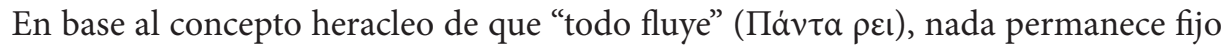
en un devenir continuo en "armonía de contrarios, como la armonía del arco y la lira” (Heracliti Ephesii Reliquiae, XLV), ${ }^{4}$ Damon consideraba al sonido y el alma como movimiento, y por ello la correspondencia directa e influencia recíproca entre música y carácter. Su teoría planteaba una estrecha relación entre las leyes constitutivas del sonido y la conducta humana, ya que la música tenía la facultad de intervenir en la paz o la agitación del alma, en el orden interior (củvouía), en una especie de isomorfismo entre los tonos de la melodía y los estados afectivos. De ahí la importancia de la música para la formación del espíritu, de la paideia [ $\pi \alpha \iota \delta \varepsilon \grave{a}]$, el ideal educativo griego (Else; Panaiotidi).

En Timeo Platón esboza la teoría ético-musical de Damon en la elucidación de Timeo de Lócride sobre la formación del universo, de indudable origen pitagórico:

Y acerca de la voz y el oído, [...] cuanto de la música utiliza la voz para ser escuchado ha sido dado por la armonía. Ésta, como tiene movimientos afines a las revoluciones que poseemos en nuestra alma, fue otorgada por las Musas al que se sirve de ellas con inteligencia, no para un placer irracional, como parece ser utilizada ahora, sino como aliada para ordenar la revolución disarmónica de nuestra alma y acordarla consigo misma. También nos otorgaron el ritmo por las mismas razones, como ayuda en el estado sin medida y carente de gracia en el que se encuentra la mayoría de nosotros (47).

Pero la teoría del éthos no se limitaba a la poesía cantada, a la ritmo-entonación en la voz del aedo, del poeta encargado de transmitir el saber mítico de las musas hijas de la memoria. La teoría se refería también al carácter de la armonía de los sonidos en su interrelación diastemático-instrumental, con su capacidad de imitar un determinado modo de ser, basado en la práctica musical de su tiempo. Si en el Período Arcaico la poesía cantada, acompañada de cítara o forminge, era el principal medio de expresión musical, en el Período Clásico además del teatro, la aulética

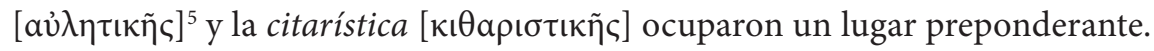

\footnotetext{
$4 \pi a \lambda i v \tau \rho$ o

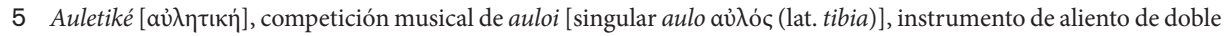
lengüeta hecho con dos tubos de marfil o bronce, a veces de diferente longitud tocados simultáneamente. Para tañer

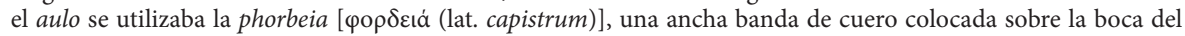
auleta y sujetada en la nuca, con agujeros para permitir el paso de las boquillas. La phorbeia mantenía la boquilla en la boca, obligando al auleta a respirar por la nariz (respiración continua), y reducir así la tensión muscular de las mejillas. Esto permitía una interpretación potente y continua. La estructura dual de dos tubos produce una ejecución antifonal de dos voces. Uno produce la melodía mientras otro una especie de zumbido en calidad de bajo
} 


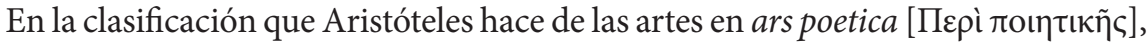
coloca entre las imitativas a la tragedia, la comedia, la lírica y la épica, en lugar de agruparlas al concepto general de la poesía. Así mismo, distinguió la aulética y la

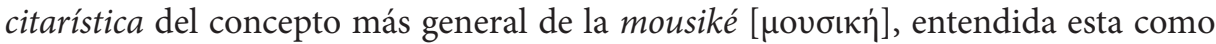
poesía cantada:

La poesía épica, entonces, y la poesía del drama trágico, y aún más, la comedia y la poesía ditirámbica, y sobre todo la aulética y la citarística se puede decir en general que son representaciones de la vida. Pero difieren una de la otra de tres formas: o bien difieren genéricamente en los medios usados, o en representar objetos distintos, o bien, en representar objetos no de la misma manera sino de manera diferente (i, 1447a 13-18).

Aristóteles clasifica a la aulética y citarística como un arte imitativo capaz de representar la vida, al igual que la poesía épica, la tragedia o la comedia. A pesar de haberse escindido de la palabra en su servil papel de solo acompañar la ritmo-entonación de la poesía, la aulética y citarística mantuvieron su capacidad de representar o de imitar la realidad y la fantasía. Esto se debe a su origen, relacionado con las representaciones de los certámenes musicales en los juegos Píticos de Delfos, cristalizados en el nomos Píticos y nomos Policéfalo, como veremos más adelante.

\section{Mousikoi Agones}

Uno de los aspectos centrales de la cultura musical griega fue el torneo (agón [ả el desafío o disputa formal que tiene lugar entre dos personajes. En el teatro fue la base sobre la cual se construyó la acción dramática. Y al igual que los míticos certámenes musicales, producto de la disputa entre los dioses con sus presunciones y caprichos, en la realidad histórica existieron certámenes poético-musicales dedicados a los dioses, e inspirados en el mitología misma. Estos fueron relatados por poetas e historiadores, como el autor del Certamen, obra anónima del siglo iI d.C., quien afirma que Hesíodo y Homero fueron contrincantes en un concurso poético-musical en Calcis, durante los funerales del rey Anfidamante (Hesíodo, Certamen 63-74).

El primer certamen musical fue el de los juegos Píticos, concurso de habilidades musicales celebrado en Delfos en honor al dios Apolo. Estos juegos, de carácter fúnebre (agón epitafios [ả $\gamma \omega \dot{v} v \dot{\varepsilon} \pi \iota \tau \dot{\alpha} \varphi$ เoc]), se realizaban en conmemoración de la muerte del dragón Pitón (Python [ПuӨเov]), y de ahí el nombre de Píticos. El mito dice que los

(Bourdon), como la gaita. El instrumento es de origen frigio. Plutarco (De musica v) y Julio Pólux (Onomasticon iv. 74 sq.) lo consideran de origen asiático o egipcio. Ateneo de Náucratis (s. II d.C.), cita un tratado del peripatético

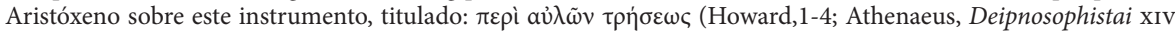
36, 634f; Bélis, 205-212; Paquette 264-65). 
juegos fueron establecidos por el propio dios Apolo tras su victoria sobre el dragón Pitón, monstruo ctónico hijo de la diosa Gea (Гaĩa, la madre tierra), que vivía en una caverna al pie del monte Parnaso, lugar del oráculo de Delfos (Hygini, Fabulae 140; Fontenrose 43-53).

En Metamorfosis, del poeta romano Publio Ovidio Nasón (43 a.c.-17 d.c.), se describe la victoria de Apolo sobre La sierpe Pitón:

Ella ciertamente no lo querría, pero a ti también, máximo Pitón, entonces te engendró, y de los pueblos nuevos, desconocida sierpe, el terror eras: tan grande espacio de un monte ocupabas. A él el dios señor del arco, y que nunca tales armas antes sino en los gamos y corzas fugaces había usado, hundido por mil disparos, exhausta casi su aljaba, lo perdió, derramándose por sus heridas negras su veneno. Y para que de esa obra la fama no pudiera destruir la antigüedad, instituyó, sagrados, de reiterado certamen, unos juegos, Pitios con el nombre de la domada serpiente llamados. Ese de los jóvenes quien con su mano, sus pies o a rueda venciera, de fronda de encina cobraba un galardón. Todavía laurel no había, y, hermosas con su largo pelo sus sienes ceñía de cualquier árbol Febo (i, 438-51).

Tras apoderarse de su sabiduría y presidir el oráculo, Apolo guardó las cenizas de Pitón en un sarcófago y fundó en su honor los juegos fúnebres llamados Píticos. Se dice que el sarcófago se haya enterrado bajo el ómfalos [ỏ $\mu \varphi \alpha \lambda$ ćc] del templo de Apolo en Delfos, piedra en forma de medio huevo y cuyo nombre significa "ombligo del mundo". Según la leyenda, la piedra fue puesta por Zeus en el templo de Apolo,

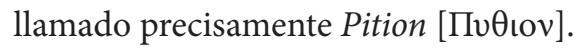

En Quaestiones Graecae, Plutarco afirma que en Delfos se celebraba cada ocho años la victoria del dios Apolo sobre el dragón Pitón, mediante la representación de esta lucha en una fiesta de carácter mistérico llamada Septerion (12). Después de matar al dragón, Apolo se aleja al valle del Tempe en Tesalia septentrional, para ser purificado por Carmanor. Una versión del mito afirma que Apolo huyó porque deseaba purificarse a consecuencia de la matanza que había hecho, otra que persiguió al dragón herido tras huir por el camino que conocemos ahora como la vía Sacra. Lo alcanzó cuando ya había muerto por el efecto de las heridas, y fue sepultado por su hijo Aix [A’ ], cuyo nombre significa "la cabra".

Los Delfos celebraban tres festivales cada ocho años: Septerion [ $\Sigma \varepsilon \pi \tau \eta \dot{\rho} ı$ เov],

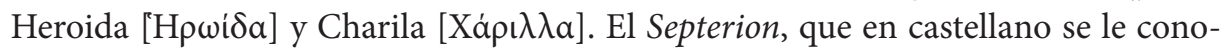
ce como Estepterio o "fiesta de las coronas", era la primera ceremonia mistérica de purificación en Delfos que antecedía a los juegos Píticos. La ceremonia permitía la participación de los iniciados y constaba de dos partes. Una transcurría en el valle del Tempe, en Tesalia septentrional, a donde Apolo fue a purificarse después de matar al Pitón. La otra en el templo de Delfos, en donde se construía junto al pórtico una cabaña de madera que representaba la cueva del dragón. Un joven, cuyos padres aún 
vivían, entraba a la plaza con su séquito de antorchas, prendían fuego a la cabaña, y sin volver atrás, huían del recinto sagrado hasta el valle del Tempe, donde se purificaban en el río y ofrecían sacrificios (Fontenrose 577-87). Plutarco describe esta ceremonia en De defectu oraculum:

"Esto", dijo Kleombrotos, "ha tenido que ver aquí con el oráculo, y que en la ciudad recientemente iniciaron todos los griegos del este de las Termopilas, y se han extendido los ritos tan lejos como Tempe. Por la estructura que es erigida aquí, cerca de la era cada ocho años, no es como el nido de la guarida del dragón, sino una copia de la morada de un rey despótico. Esto inicia en silencio a través de un camino llamado "Camino de Dolonia", por el cual con antorchas encendidas conducen al muchacho, quien debe tener a los dos padres vivos, y después, prenden fuego a la estructura y tiran la mesa, huyendo a través de las puertas del templo sin mirar atrás. Finalmente, los errantes y esclavos del muchacho, y su purificación tiene lugar en Tempe. Todo esto apunta a suponer que se trata del atrevimiento de una gran actuación profana [traducido por el autor] (15).

En Descripción de Grecia Pausanias narra los certámenes musicales de Delfos, refiriéndose a un período mítico anterior al establecimiento real de los juegos Píticos. En estos participaron Filamón -hijo de Apolo-, su hijo Támiris, y menciona a Orfeo $\mathrm{y}$ al aedo Museo, quienes se negaron a participar:

El certamen más antiguo que tuvo lugar y en el que se establecieron premios por primera vez recuerdan que fue el cantar un himno al dios. Cantó y venció en el canto Crisótemis de Creta, cuyo padre Carmánor se dice que purificó a Apolo. Después de Crisótemis recuerdan que venció en el canto Filamón, y después de aquél, Támiris, hijo de Filamón. Pero dicen que no quisieron someterse a prueba en un certamen de música Orfeo, por la jactancia con sus misterios y a causa de su orgullo, ni Museo, por imitar en todo a Orfeo (x. 7. 2).

Al igual que en el certamen de Calcis, Pausanias añade que Homero y Hesíodo participaron en el concurso de Delfos sin mucho éxito:

Dicen también que Eleuter, que tenía una voz alta y dulce no obtuvo una victoria pítica porque no cantó una canción suya. Se dice también que Hesíodo fue excluido del certamen porque no había aprendido a acompañar con la cítara su canto. Homero llegó a Delfos a preguntar lo que necesitaba, pero aunque hubiera aprendido a tocar la cítara, su conocimiento le habría sido inútil por la pérdida de la vista (x. 7.3).

El comentario de Pausanias sobre la habilidad inútil desarrollada por Homero para tocar la cítara, debido a su ceguera, es muy interesante, ya que pone en evidencia la finalidad del concurso, esto es, la demostración de habilidades musicales y no la inspiración divina de las Musas. En Grecia, la ceguera era considerada un don 
otorgado al aedo como estímulo de la memoria, y no por sus habilidades como instrumentista (García 75-6).

Los juegos Píticos formaron parte de los juegos panhelénicos celebrados cada Olimpiada, es decir, cada cuatro años. ${ }^{6}$ Tomaron su forma definitiva después de la primera guerra sagrada. Cuando los pobladores de Krisa quisieron apoderarse del santuario de Delfos, sus habitantes pidieron ayuda a los anfictiones, un grupo de doce etnias que administraron el santuario de Delfos a partir de 590 a.C., restableciendo el agón en honor a Apolo (Pausanias x. 8. 2).

En la Crónica de Paros [Xpovıkòv Mápıov], lápida que contiene la cronología griega que va del 1582 al 264 a. C., se dice que los juegos Píticos iniciaron en el año 590 a. C., teniendo lugar el agón hímnico, competición hímnica premiada con botín de guerra. Pero desde el 582 a.C., su premio consistió únicamente de una corona de laurel.

[Desde que] los an[fict]iones [se sacrificaron] después de vencer Kyrrha, y el concurso gimnástico se estableció con un premio monetario de los botines, 7 años, cuando Simón fue archon en Atenas. Desde entonces el concurso [por la co]rona fue establecida nuevamente, 318 años, cuando el segundo Damasius fue archon en Atenas [traducido por el autor] (Das Marmor Parium, Fragmentum A, 37, 38).

Originalmente los juegos Píticos, al igual que el Septerion, se celebraba cada ocho años, pero a partir del 590 a.C. se celebró cada Olimpiada. Pausanias afirma que en el tercer año de la $48^{\circ}$ Olimpiada, esto es, en el 586 a. C.:

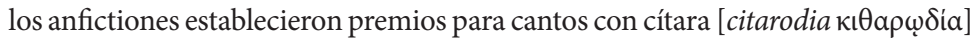
como al principio y añadieron un certamen de canto con flauta y de flautas

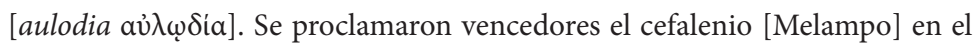
canto con cítara [citarodia], y en el canto con flauta [aulodia] Equémbroto de Arcadia, y Sácadas de Argos en la flauta [aulo aủ入óc]. Este Sácadas se llevó también victorias en los dos siguientes Juegos Píticos. (x. 7. 4)

Pausanias también menciona que en ese segundo certamen se ofrecieron por primera vez coronas para los atletas, tal como se ofrecían en las competiciones de los juegos de Olimpia, excepto por la cuadriga -carrera en carro de cuatro caballos-:

En los segundos Juegos Píticos no se ofrecieron ya premios para las competiciones, sino que se estableció el certamen con coronas desde entonces. Eliminaron también el canto con flautas [aulodia], pensando que no era de buen agüero oírlo. En efecto, los cantos con flauta constan de las más tristes melodías de flauta $[a u l o]$ y de los cantos fúnebres [lamentaciones, $\theta \rho \tilde{v}$ vol] acompañados de flautas [auloi] (x. 7.5).

6 Olimpiada: unidad de tiempo en el periodo helénico a partir del historiador Éforo de Cime (ca. 400-330 a. c.). Según este recuento, la primera Olimpiada transcurrió del verano de 776 al 772 a. c. del calendario juliano. 
En total, los juegos Píticos duraban de seis a ocho días más que los Olímpicos, ya que incluían los certámenes poético-musicales. Los tres primeros días se dedicaban a los sacrificios, procesiones, y a la representación dramática de la lucha de Apolo con el dragón Pitón, similar al Septerion. Al cuarto día se establecía el certamen musical

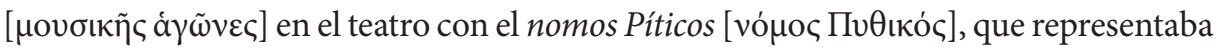
la lucha del dios Apolo con el dragón Pitón. No obstante, Plutarco señala como un grave error que los sacerdotes del templo permitieran a poetas y escritores mostrar en los teatros sus competiciones, ya que atentaban contra lo más sagrado del rito que ellos mismos interpretaban (De defectu oraculum 15).

\section{Nomos}

El nomos fue un género musical en dos estilos. El primero poético-vocal de dos tipos:

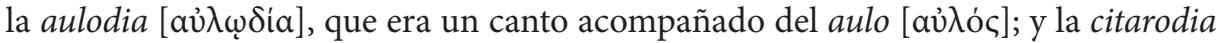

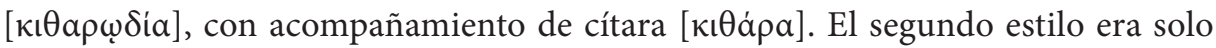

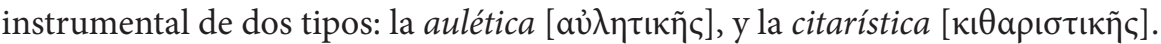

El nomos está íntimamente ligado a la mitología y los rituales llevados a cabo en los principales centros ceremoniales de Grecia. Es por ello que en la mayoría de los testimonios e historias sobre la práctica musical real de la antigua Grecia, se entremezclan el mito y la realidad histórica. Esto debido a que el recurso retórico de la metonimia es recurrente, y en donde al personaje mítico se le reconoce como el autor de la obra anónima. La homonimia o duplicidad de los personaje, -a través de confusas genealogías - propicia cruzar la delgada línea entre lo mitológico y la realidad histórica arcaica. Tal es el caso de Olimpo de Misia, auleta y compositor frigio del noroeste de Anatolia, Asia Menor. Se dice que él introdujo la música instrumental

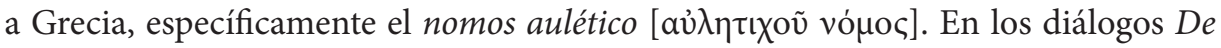
musica atribuidos a Plutarco, ${ }^{7}$ se afirma que:

Alejandro, en su Libro sobre Frigia, ha dicho que Olimpo fue el primero en introducir la música instrumental entre los griegos, aunque lo hicieron los Dáctilos Ideos. Que el primero que tocó el aulo [aủ入óc] fue Hiagnis, después su hijo Marsias, y después Olimpo (1132e10-f 2 [c. 5]).

El relato está basado en la obra del gramático de Mileto Cornelio Alejandro (ca.100 a.C.), quien indistintamente atribuye la introducción de la música instrumental a Grecia a personajes míticos, como los Dáctilos del monte Ida o a la ambigüedad genealógica de Hiagnis, Marsias y Olimpo, todos ellos frigios. Esto nos muestra que

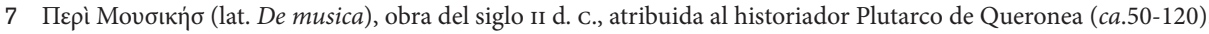
La obra se estructura como un diálogo entre eruditos invitados al banquete de las fiestas saturnales, en el que el anfitrión, Onesícrates, les pide a sus invitados Lisias y Sotérico contarle a sus amigos "quien fue el primero que trajo la música en uso" y sus más famosos exponentes (Plutarco, De musica 9-26). 
el mito y la práctica musical del nomos tuvieron una estrecha relación en el Período Arcaico, determinando en gran medida el desarrollo de los géneros musicales griegos.

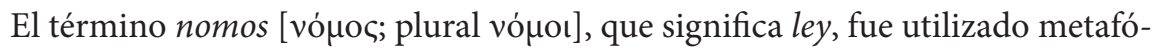
ricamente en el contexto musical griego para establecer formas rigurosas de cantos destinados a diferentes ceremonias, construidos de acuerdo con un modo musical [ảpuovía] determinado de antemano, y en correspondencia con algún ethos o situación emotiva específica. El término equivaldría a melodía, motivo o tema. En el Período Clásico los nomoi representaron la tradición musical más rigurosa, vinculados al ideal pedagógico de la paideia, que le otorgaba a la música una función ética y, por tanto, formadora del espíritu griego.

El nomos fue uno de los cuatro géneros musicales más importantes de la Grecia arcaica y clásica, junto al himno, el peán y el ditirambo, que Platón relata en Leyes:

Ateniense.- En primer lugar, a las que entonces regulaban la música, para que expongamos desde el comienzo el progreso excesivo de la forma de vida libre. En efecto, entre nosotros, la música se encontraba entonces dividida en ciertos géneros y estilos. Una clase de canciones eran las plegarias a los dioses que

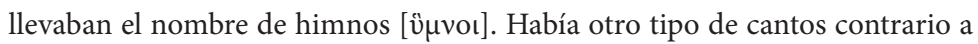
esta -se les hubiera podido dar muy bien el nombre de trenos [ $\theta$ pŕvovc], otra eran los peanes [ $\pi \alpha i \omega v \varepsilon \varsigma$ ] y otra, alabanza de Dioniso, creo, llamada ditirambo

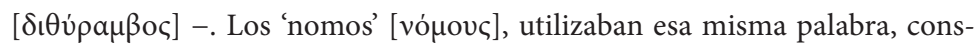
tituían como otra especie de clase. Y les agregaban "acompañados de cítara"

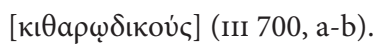

Proclus afirma que el peán, canto coral en honor a Apolo, fue sustituido por el nomos citaródico, canto acompañado de cítara. ${ }^{8} \mathrm{El}$ nomos fue compuesto originalmente en honor a Apolo, ya que el epíteto de Apolo Nó $\mu$ нь -antiguamente usado en lugar

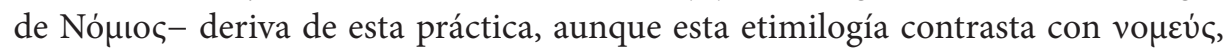
implicando que Apolo es el dios pastor (Photii, Bibliotheca II 239]: 320A35; Edmonds, Lyra Graeca 291; Rutherford 356). Según Proclus, el nomos fue inventado en Delfos, cuando Crisótemis de Creta, primer laureado en los juegos Píticos, estableció la práctica instrumental llevando la cítara en imitación de Apolo: "pero Crisótemis de Creta primero adoptó un vestido distintivo, y tomando la lira en sus manos para representar a Apolo cantó el nomos solo, y como ganó fama por esta interpretación, la competición ha sido hasta ahora de este tipo [traducido por el autor]" (Photii, Bibliotheca 239: 320B1ss; Edmonds, Lyra Graeca 292-93).

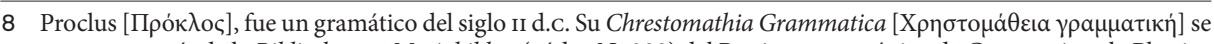
conoce a través de la Bibliotheca o Myriobiblon (códex № 239) del Patriarca ecuménico de Constantinopla Photius (ca.810- ca.893), una extensa colección de 280 escritos del siglo Ix d. c., sobre autores clásicos griegos. Photius

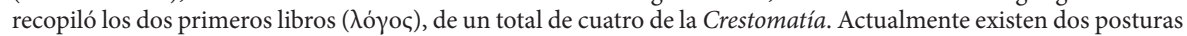
sobre la identidad del autor. Se le ha identificado como un gramático del siglo ir d.C., aunque algunos investigadores lo identifican con el neoplatónico de Constantinopla Proclo (410-485 d. c.) (Severyns; Longo). 
La mayoría de los poetas que conformaron el nomos fueron originarios de la isla de Lesbos, al noreste del mar Egeo. Proclus afirma que Terpandro de Antissa ( $f l$ ca.675 a. c.) lo perfeccionó, agregando un canto heroico; Arión de Metimma (s. vII a. c.) le aumentó un poco en la poesía misma y en la citarística; Phrynis de Mytilene (ca.450-420 a. c.) lo alteró, e hizo innovaciones combinando el hexámetro por el metro de tipo libre y el uso de más de siete cuerdas. Finalmente, Timoteo de Miletus (ca.450-360 a. c.) fue quien lo llevó a su forma definitiva.

\title{
Ditirambo
}

Proclus contrasta el nomos con el ditirambo dionisiaco, que está lleno de movimiento y expresa un alto grado de "posesión" por medio de la danza, dirigido a evocar las emociones más características del dios Dioniso, ya que también es salvaje en sus ritmos y emplea una fraseología simple. El nomos en cambio, se sustenta en el orden y dignifica el estilo por los caracteres que describe, mientras sus ritmos son tranquilos, empleando expresiones compuestas (Photii, Bibliotheca, 239:320B6-19ss; Edmonds, Lyra Graeca 293).

El ditirambo y el nomos eran posiblemente en sus inicios muy similares. En Clío, primer libro de la Historiae de Herodoto de Halicarnaso (484-425 a. c.), se afirma que Arión de Metimma, a quien milagrosamente rescató del mar un delfín en el cabo Ténaro, era conocido como un excelente cantor con la lira y el primer compositor de ditirambos (I 23-24; Edmonds, Lyra Graeca 137).

Proclus confirma que "de acuerdo con Píndaro, el ditirambo fue inventado en Corintia, y Aristóteles nos dice que el creador de este canto fue Arión, el primer instructor del coro circular o cíclico" [traducido por el autor] (Photii, Bibliotheca 239: 320A30; Edmonds, Lyra Graeca 139). En la Suda o Lexicón, enciclopedia bizantina del siglo $\mathrm{x}$ atribuida al lexicógrafo Suidas (ca.976-1028), se afirma que:

\begin{abstract}
Arion ['Apí $\omega v$ ] De Metimma, poeta lírico hijo de Kykleus, nació en la treintaiochoava Olimpiada [628-624 a.C.]. Se dice que fue incluso discípulo de Alcmán. Compuso cantos en dos libros de preludios para poemas épicos. Se dice también que él fue el inventor del estilo trágico, y haber sido el primero en formar un coro para cantar ditirambos, de dar el nombre al canto del coro, y de introducir sátiros hablando en verso [traducido por el autor] (Suidae, 716; Edmonds, Lyra Graeca 139).
\end{abstract}

Es probable que Arión de Metimma tomara la ditirámbica invocación, consistente en gritos rituales llamando a Dioniso, dándole forma artística, tanto literaria como musical. En definitiva, Arión hizo que el coro cantara un poema regular con un objeto definido, tomando el nombre de ditirambo (Pickard-Cambridge 12). En los diálogos De musica de Plutarco se sugiere que Timoteo de Miletus (450-360 a. c.) usaba la dicción ditirámbica en su nomos: 


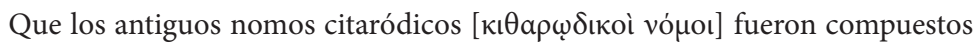
en hexámetros, lo demostró Timoteo: cantaba en efecto, sus primeros nomos en hexámetros, mientras que mezclaba en ellos la dicción ditirámbica

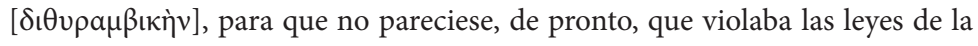
música antigua (1132d8-e2 [c. 4]).

Desde el punto de vista musical, Proclus afirma que el ditirambo es interpretado en el modo [ả $\mu$ ovía] frigio e hipofrigio, y el nomos en el sistema lidio de los cantores con cítara (Photii, Bibliotheca, 239: 320B15ss; Edmonds, Lyra Graeca 293). La relación del ditirambo con el modo frigio era tradicional, pero la del nomos con el modo lidio se relaciona más bien con el peán de carácter fúnebre, como lo atestigua Plutarco en De musica:

Otros afirman que el mismo dios tocaba el aulo, como lo cuenta el excelente poeta lírico Alcmán. Y Corina afirma que Atenea enseño a Apolo a tocar el aulo. Así, la música, en todos los aspectos, es venerable, por ser una invención de los dioses. Los antiguos practicaron la música, como todas sus otras actividades, de acuerdo con su dignidad; los modernos, en cambio, rechazando sus aspectos más venerables, en lugar de aquella música viril, inspirada y querida a los dioses introducen en los teatros una música afeminada y seductora. Por eso Platón, en el libro III de su República, muestra su rechazo a esa clase de música; desaprueba por ejemplo, el modo lidio, por ser agudo y apropiado para las lamentaciones. Se dice que la primera composición en modo lidio fue a modo de lamento.

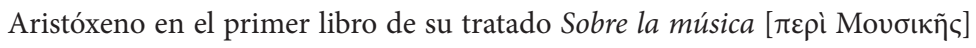
afirma que Olimpo fue el primero que tocó al aulo, en modo lidio, un canto fúnebre en honor de Pitón. Hay quienes afirman que Melanípides comenzó con este tipo de melodía (1136b-c 7 [c. 14-15]).

En términos de su origen, el ditirambo proviene del juego y la embriaguez, mientras el nomos surge del orden del peán reverencial de Delfos. Proclus afirma que:

El ditirambo parece haber surgido de las festividades del campo y las borracheras de boda, mientras el nomos probablemente deriva del peán, siendo el primero generalmente una súplica para apartar el mal, y el último una apelación privada y personal a Apolo. De ahí que el nomos no tiene el elemento de 'posesión' que se encuentra en el ditirambo. Mientras que en aquél encontramos bebida y diversión, en el nomos encontramos súplica y gran orden, ya que la verdadera deidad interesada impregna a la música que es construida ordenada y sistemáticamente [traducido por el autor] (Photii, Bibliotheca, 239: 320B21ss; Edmonds 1927, 293).

Así, de acuerdo con Proclus, la evolución del nomos genera la siguiente secuencia: a) peán coral; b) nomos coral; y, c) nomos solo. De este último surge el nomos Píticos [vó ПレӨเкóৎ], una de las primeras formas musicales de la historia con un programa definido. 


\section{Nomos Píticos}

El nomos Píticos era un nomos aulético, es decir, una obra instrumental para aulo de cinco partes, y cuyo argumento poiético era la representación mimética de la lucha del dios Apolo con el dragón Pitón, en una especie de drama musical basado en el mito y el ritual del Septerion. Estrabón de Amasia (ca.64a. c.-ca.24 d.c.) describe en el tercer capítulo del noveno libro de su Geográfica al nomos Píticos:

En cuanto al certamen [ả $\gamma \grave{\omega} v]$ en Delfos, había antiguamente entre los citaredos

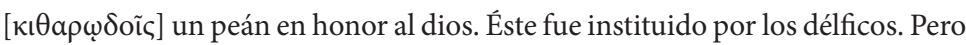
después de la guerra de Krisa, en tiempos de Euriloco, los anfictiones establecieron un concurso hípico y atlético, en el cual el premio era una corona, y lo

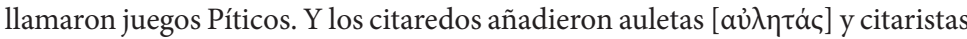

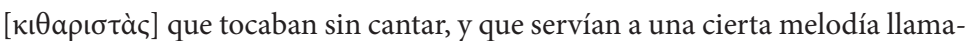

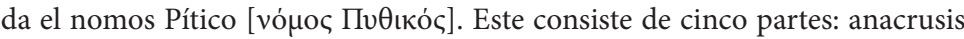

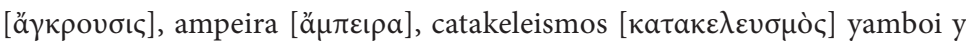

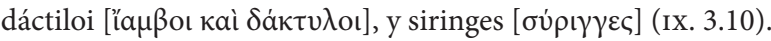

Los citaredos eran citaristas que acompañaban su propio canto, llamado citarodia

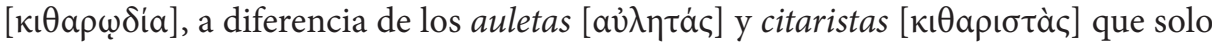

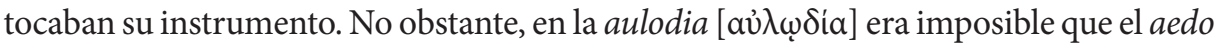
mismo acompañara su canto con el aulo, y tenía que ser asistido del auleta. En el mito, este fue el motivo por el cual las Musas le otorgaron la victoria a Apolo sobre Marsias, ya que el sátiro no pudo cantar y soplar el aulo al mismo tiempo (Diodorus Siculus, Bibliotheca historica, III. 59). En la realidad histórica, Equémbroto fue acompañado por el auleta Sácadas de Argos en la aulodia del primer certamen de los juegos Píticos.

Estrabón menciona que el nomos Píticos fue compuesto por Timostenes ( $f l$-270 a. c.), geógrafo y célebre navegante de la flota del rey Ptolomeo in Filadelfos de Egipto: Ahora la melodía fue compuesta por Timostenes, almirante del segundo Ptolo-

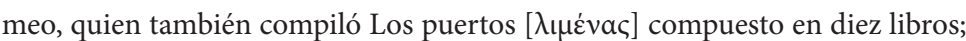
y a través de esta melodía él pretende celebrar la lucha entre Apolo y el dragón

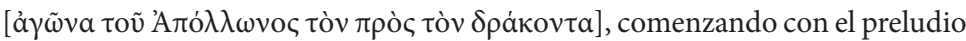
como anacrusis. La primera irrupción de la lucha como amperia. La lucha misma como catakeleismos. El triunfo después de la victoria como yamboi y dáctiloi. El ritmo inicia en dos medidas. Una de ellas, el dáctilo, es apropiado para el himno de alabanzas, mientras que el otro, el yámbico, es adecuado para el reproche.

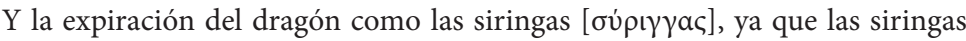
tocan imitando al dragón, cómo este respira en su último chasquido (IX. 3.10).

Estrabón tal vez se refería a la interpretación del nomos Píticos en su época, y no a su composición, ya que fue obra del auleta Sácadas de Argos, compuesta unos trecientos años antes de Timostenes, con la que obtuvo la victoria en la aulética del tercer cer- 
tamen de los juegos Píticos en 574 a.C. En De musica Plutarco menciona a Sácadas de Argos como vencedor de los juegos Píticos, pero no como autor del nomos Píticos: En efecto, al principio, los aulodos cantaban versos elegíacos compuestos con música; esto lo demuestra la inscripción de las Panateneas sobre el concurso musical. Sácadas de Argos fue también un compositor de melodías y de versos elegíacos con música; éste fue también un buen auleta y se le recuerda como vencedor en tres ocasiones en los juegos Píticos (1134a 1-6 [c. 8]).

En Onomasticon [Ovouaçıкov], del retórico alejandrino Julio Pólux (s. II d. c.), también se atribuye el nomos Píticos al argivo Sácadas, que describe de la siguiente manera:

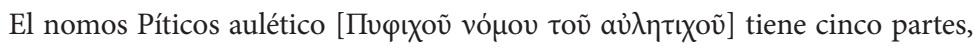

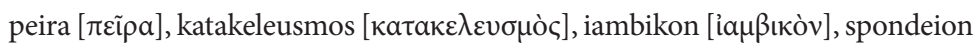

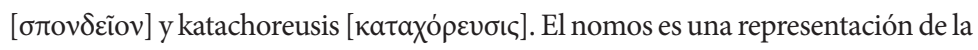
batalla de Apolo con el dragón. En la peira ['prueba’ o 'juicio’] él estudia el campo para ver si éste es apropiado para el combate. En el katakeleusmos ['desafío'] él llama al dragón, y en el iambikon luchan; el iambikon también incluye sonidos como aquellos del salpin $x[\sigma \alpha \lambda \pi \iota \sigma \tau \kappa k \grave{]}$ y rechinidos como los del dragón cuando aprieta los colmillos después de ser herido con flechas. El spondeion representa la victoria del dios; y en el katachoreusis el dios ejecuta la danza de victoria [traducido por el autor] (Pollucis, Onomasticon, IV, 84; Barker, I:51).

En Descripción de Grecia, Pausanias también atribuye el nomos Píticos a Sácadas de Argos: "En efecto, Sácadas ganó en los juegos organizados por los anfictiones, cuando todavía no se adjudicaban coronas, y después de esta victoria otras dos, por las que ya recibió coronas" (vi.14.10). Pausanias afirma que Sácadas adquirió una gran reputación como auleta, obteniendo en Delfos tres victorias consecutivas: en el año 582; 578; y 574 a. c.

Estrabón menciona que antes del año 576 a. c., los peanes citaródicos se tocaban en Delfos, para ser reemplazados más tarde por el aulético nomos píticos, quedando la secuencia del nomos, al parecer, de la siguiente manera: a) peán coral; b) peán solo; c) nomos coral; y, d) nomos solo. Por otra parte, Proclus parece haber modificado la oposición común entre el ditirambo y el peán. En su exposición sobre el origen del nomos solo, afirma que este surge del nomos coral de Delfos, ya que el peán, además de ser dirigido al dios Apolo y su hermana Artemisa, también podía ser dirigido a cualquier otra deidad, debido a su función apotropaica. ${ }^{9}$

9 Las cualidades apotropaica y profética de Apolo parecen relacionarlo con la música, concretamente con el peán

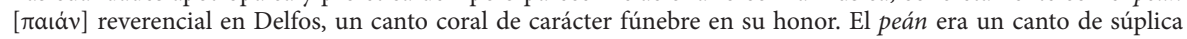
dirigido al dios sanador Apolo para apartar el mal, plagas y enfermedades, y de ahí su función apotropaica. Por una parte el oráculo de Delfos lo relaciona con el deseo de saber el desenlace de una enfermedad, y ésta a su vez, con su poder apotropaico de apartarla. Es por ello que a Apolo se le identificó también con el dios sanador micénico Peán [Пaı́vv]. En la Odisea Homero cita al Dios Peán (Odisea 227-32), aunque también distingue Apolo Peán de Peón (Paiéon [Пaı́ $\omega v]$ ), el sanador de las heridas de Ares y Hades en la Ilíada (899-901). 
Ian Rutherford afirma que el nomos citaródico usurpó el lugar del peán, debido a que este era un género inapropiado a Apolo. En primer lugar, porque el peán era muy diverso, es decir, dedicado a cualquier deidad, y no se percibió más como un símbolo digno de Apolo. También porque este pertenecía a un período más arcáico, comparado con el nomos artísticamente más elaborado. Otro aspecto era el término mismo vó $\mu$ oৎ que significa ley, y que sugiere el principio de orden que Apolo supuestamente mantenía, y que se reflejaba en su epíteto Nó interpretación euhemerista de Éforo de Cime (ca.400-330 a. c.) sobre la desmitificación del inmortal civilizado.

Tal vez por ello a lo largo de cuatro siglos de fuentes literarias antiguas, se asoció el nombre de este género musical con la idea de ley, y se le reconoce a Apolo como el legislador en este periodo. Más aún, el nomos solo -canto con acompañamiento instrumental- fue un símbolo más apropiado para Apolo, ya que este Dios siempre fue representado con su cítara, como símbolo de la unidad, en contraste con el ditirambo dionisiaco, que representa la canción coral comunal más cercana al juego y la comicidad (Rutherford 360).

Como mencionamos anteriormente, se han identificado cuatro tipos diferentes de nomos solo, asociados al virtuosismo instrumental con o sin la participación del canto. Estos son: nomos citaródico y citarístico; y, nomos aulódico y aulético. El nomos citaródico, que era un canto con acompañamiento de lira o cítara [ $\kappa \imath \theta \dot{\alpha} \rho \alpha]$, fue instaurado por Terpandro en Lesbos, quien le dio su forma canónica. Pero su origen es ciertamente mítico.

Plutarco cita al astrónomo Heraclides de Ponto (ca.390-310 a. c.), quien menciona en su Catálogo de músicos famosos: "el canto con la cítara y la composición citarística los practicó primero Anfión, el hijo de Zeus y de Antíope, que tuvo como maestro evidentemente a su padre" (De musica 1131f 5-1132a1 [c. 3]). Según Pólux, el nomos citaródico compuesto por Terpandro constaba de siete partes: a) el inicio llamado archa

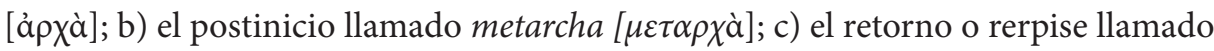

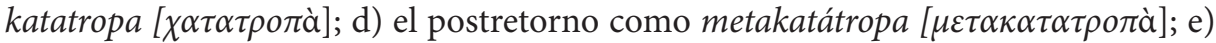
la parte media llamada ómfalos [ỏ $\mu$ àòc]; f) el cierre o sentencia llamado esfragis

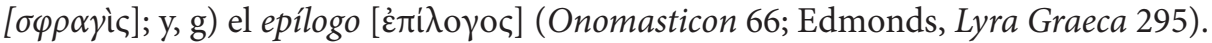

El nomos aulódico es asociado a Clonas, un seguidor de Terpandro. En De musica, nuevamente citando a Heraclides, se menciona a Clonas como el inventor de un canto procesional de camino hacia el templo con acompañamiento del aulo, llamado prosodia $[\pi \rho \circ \sigma o ́ \delta ı]$.

Y afirmaba Heraclides que Terpandro, que era un compositor de nomos citaródicos, ponía música, apropiada a cada nomo[s], a los hexámetros compuestos por él y a los de Homero, y los cantaba en los concursos. Dice que éste fue el primero en dar nombre a los nomos citaródicos, y que como Terpandro, Clonas,

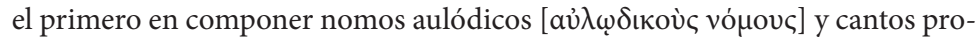
cesionales [ $\pi \rho \circ \sigma o ́ \delta ı \alpha]$, fue un poeta de versos elegíacos y épicos (1132c [c. 3]). 
No obstante, el mismo Plutarco pone en duda lo dicho por Heraclides, diciendo que: Algunos otros escritores afirman que Árdalo de Trecén compuso música para ser cantada con aulo antes que Clonas y que hubo también un compositor llamado Polimnesto, hijo de Meles de Colofón, que compuso los Nomos Polimnesto. De Clonas los autores de inscripciones recuerdan que compuso el Nomo Apóthetos

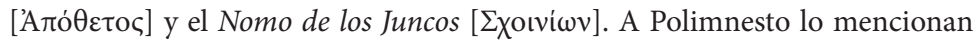
también Píndaro y Alcmán, poetas líricos. Y algunos de los nomos citaródicos compuestos por Terpandro dicen que son obra del antiguo Filamón de Delfos (1133a-b 3 [c.5]).

En general son siete tipos de nomos citaródico, que el primer poeta músico no mítico de Grecia, Terpandro, llamó: Boecio; Eolio; Troqueo; Agudo; de Cepión; de Terpandro; y Tetraoídion. El nomos aulódico es posterior, y son seis: Apóthetos [Ađó $\theta \varepsilon \tau o \varsigma]$ "tenido

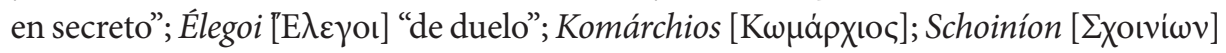

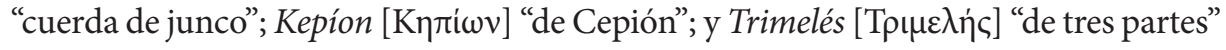
(Plutarco, De musica 1132d [c. 4]).

Los nomoi instrumentales son muy posteriores al nomos aulódico y citaródico, lo que refleja el desarrollo ulterior de las habilidades artístico-instrumentales en el siglo vi a.c. Diversas fuentes confirman que el nomos citarístico y aulético se introdujeron a los juegos Píticos de Delfos a partir del segundo certamen en el 578 a.c. En Problemata [Про $\beta \lambda \eta \mu \alpha \tau \alpha]$, obra atribuida a Aristóteles, se afirma que el nomos fue pensado para instrumentistas virtuosos. Como su función era imitar, el nomos se diversificó y creció con una música en constante cambio para sugerir la acción dramática de la narrativa. Este nuevo nomos era una especie de música instrumental programática, creada a partir de una historia o leyenda, básicamente de carácter mítico. El libro xıx, dedicado a los Problemas relativos a la música, contiene una serie de cincuenta preguntas a las que Aristóteles da respuesta, en donde se cuestiona “¿Por qué los nomos no se componían con correspondencia estrófica y, en cambio, los demás cantos corales si?”:

¿Es porque los nomos eran propios de profesionales [ả $\gamma \omega v i \sigma \tau \tilde{\omega} v]$, cuyo canto llagaba a ser largo y variado por ser ya ellos capaces de imitar [ $\mu \Perp \varepsilon \varepsilon \tilde{\sigma} \sigma \alpha \mathrm{l}]$ y mantener la voz? Así pues, igual que las palabras, también la melodía se adecuaba a la imitación variando continuamente. Pues es más necesario imitar con la música que con las palabras. Por eso también los ditirambos, una vez que se hicieron imitativos, ya no tienen correspondencia estrófica, mientras que antes sí que tenían. La causa es que antiguamente eran los mismos hombres libres los que participaban en los coros: así que era difícil que muchos cantaran con dramatismo, de modo que cantaban juntos melodías en acorde perfecto. Pues ejecutar muchos cambios es más fácil para uno que para muchos, y para el profesional más que para quienes mantienen su forma de ser habitual. Por eso les componían las piezas musicales más sencillas. La correspondencia estrófica es algo sencillo: pues se compone de un solo ritmo y un solo metro. La causa es 
la misma de por qué las piezas representadas en la escena no tienen responsión estrófica, mientras que las del coro sí: y es que el actor es un profesional y un imitador, sin embargo, el coro imita menos (15).

Los cantos corales solían tener tres partes. Primero la "estrofa", durante la cual los coristas danzaban hacia un lado. Luego la "antistrofa" o respuesta con el mismo número de versos, en donde danzaban hacia el lado contrario, quedando en la posición inicial. Finalmente, el "epodo", compuesto por varios versos que se cantaban por si algún miembro había quedado descolocado. Según Aristóteles, Melanípedes abandonó el responsorio de la estrofa, y en lugar de antistrofa introdujo largos preludios en los que se perdía la unión en la ritmo-entonación silábica, considerada esencial hasta entonces en la entonación de la poesía épica y lírica. Esta separación entre música y letra permitió que la música por sí sola describiera la narrativa en cuestión, debido a su gran poder evocativo por medio de la imitación entonativa. Un ejemplo de ello lo menciona Aristóteles en su Retórica:

De manera similar largos periodos asume la proporción de un discurso y guardan un parecido con los preludios ditirámbicos. Esto llevó a que Demócrito de Quíos reprendiera en broma a Melanípedes, quien en lugar de antistrofas compuso preludios ditirámbicos. "Un hombre se daña a sí mismo cuando daña a otro, y un largo preludio es más mortal a quien lo compuso". Estos versos se pueden aplicar a aquellos que emplean largas oraciones (1409b 7, 5-8).

Melanípides de Melos (s. v a. c.) fue uno de los autores más notables de ditirambos, y exponente de la "nueva música" en su época. Plutarco lo coloca, junto a Eurípides, como uno de los grandes músicos. No obstante, sus innovaciones fueron muy criticadas, como constata Aristóteles en Problemata. Plutarco menciona que el poeta ático Ferécrates ( $f l 440$ a. c.) lo acusa de haber abandonado la sencillez de la música antigua, al aumentar el número de cuerdas de la lira hasta doce, lo que siguieron otros músicos del siglo v a. C., como Timoteo de Mileto entre otros:

Del mismo modo, el poeta lírico Melanípedes, que vivió después, no se mantuvo en el tipo de música tradicional, ni tampoco Filóxeno ni Timoteo. Éste, en efecto, a la lira de siete notas que había hasta Terpandro de Antisa, le incrementó el número. También la aulética cambió de una música más simple a una más compleja: antiguamente, hasta la época del compositor de ditirambos Melanípedes, los auletas acostumbraban a recibir sus salarios de los poetas, pues evidentemente la poesía era la protagonista, subordinándose los auletas a sus autores. Más tarde también esta costumbre se fue perdiendo, de modo que el poeta cómico Ferécrates puso en escena a la Música en forma de mujer, toda ella violentamente ultrajada en su cuerpo; y hace que la Justicia le pregunte la causa del ultraje, y que la Poesía diga: Te hableré de buena gana; pues para tu corazón es un placer escuchar y para el mío hablar. En efecto, mis males comenzaron con Melanípedes. Con éstos 
él fue el primero que me cogió, y me aflojó y me hizo más afeminada con sus doce cuerdas. Éste, sin embargo, era para mí un hombre soportable, en comparación con los males presentes (De musica 1141c 4-e 3 [c. 30]).

Como se puede observar, la sencillez del nomos citaródico de Terpandro (s. vil a.C.), con su lira de siete cuerdas como el número de planetas, dio paso a la complejidad instrumental de auletas y citaristas independientes cristalizada en el nomos aulético y el citarístico, con sus doce cuerdas.

Dicha transición del antiguo nomos citaródico y aulódico hacia la "nueva música" del siglo v a.C., iniciada al parecer por Laso de Hermione ${ }^{10}$ con su renovación del ditirambo hacia el final del siglo vi a.C., culmina con el nomos citarístico de Melanípedes, Filóxeno de Citera (453-380 a.c.), y Timoteo de Mileto (ca.450-360 a.c.). En la aulética, el nomos aulético inició de hecho en el 574 con el triunfo de Sácadas de Argos en el tercer certamen de los juegos Píticos, interpretando el nomos aulético denominado nomos Píticos.

Como explica Aristóteles en Problemata, al independizarse los músicos de la ritmo-entonación de la poesía épica y lírica, auletas y citaristas desarrollaron en el nomos la capacidad de imitar entonativamente con sus instrumentos a distintos personajes de la narrativa mítica. La capacidad mimética del aulo, con su potente timbre chillón para emular el siseo del dragón Pitón, permitieron al auleta Sácadas de Argos crear una pieza instrumental que relatara entonativamente la lucha entre el dios Apolo y el dragón Pitón.

Como lo describe Pólux en Onomasticon, esta obra constaba con cinco partes. Primero la peira [ $\pi \varepsilon \tilde{\rho} \rho \alpha$ ], prueba en la que Apolo estudia el campo para ver si es apro-

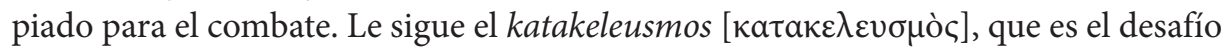

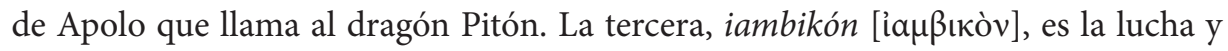
representa el rechinido de los colmillos del dragón después de ser herido por las fle-

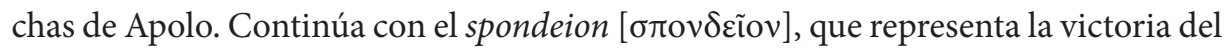

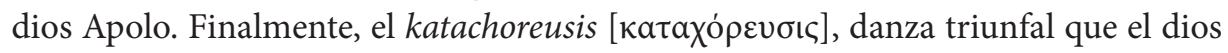
ejecuta (Pollucis, Onomasticon IV 84; Barker I 51).

\section{Nomos Policéfalo}

Otra gran obra instrumental de la aulética del siglo v a.C. es el nomos Policéfalo, basado en el mito de la invención de aulo por la diosa Atenea. Una primera versión del mito dice que la diosa arrojó el aulo en el bosque de Ida, al ver que su rostro se desfiguraba

10 Laso de Hermione (s. vi-v a.C.) fuen un compositor de himnos y ditirambos. Maestro de Píndaro. Introdujo competiciones ditirámbicas en Atenas alrededor del 508. Innovó la aulética. Aristóxeno le atribuye el primer tratado sobre música, que llamó junto a su sucesor, Eratocles, “doctrinas de los harmónicos" (Aristóxeno I 2-3). 
al tocarlo. Aristóteles cita en su Política este mito "que contaban los antiguos sobre el aulo cuando decían que Atenea, después de haberlo descubierto, lo tiró. Pudo haber sido, a lo que se dice, por el enfado que le causó a la diosa al ver que el tocar el aulo le desfiguraba el rostro" (viII 1341b 2-5).

La segunda parte del mito relata la promesa de Atenea de que sería severamente castigado quien encontrara el aulo. Marsias lo encontró, y al ser sorprendido, fue retado a duelo musical por Apolo. Otra versión del mito narra que el aulo, al emular el sonido infernal de la Gorgona Medusa, Atenea lo arrojó en el bosque para ocultar su maleficio.

En el siglo v a.C., el poeta lírico Píndaro (518-438) compuso una breve Oda en honor al auleta Midas de Agrigento por su victoria en los juegos Píticos. En su duodécima Oda Pítica, el poeta presenta a la diosa Atenea como la inventora del aulo. Después de la invocación a la ciudad natal de Midas, Píndaro disgrega sobre la invención de Atenea:

¡Yo te suplico, de esplendores amiga, tú la mas bella de las ciudades mortales, de Perséfone sede! ¡La que en las riberas del Acragas [’Aкрájaç lat. Agrigentum], criador de rebaños, habitas la bien edificada colina, oh reina! Propicia recibe, con la complacencia de Inmortales y de hombres, esta corona de Delfos para el muy glorioso Midas, y a él en persona que a Grecia venció con el arte que antaño Palas Atenea inventó, cuando el triste lamento tejió de las atrevidas Gorgonas. Este oyó de las virgíneas, inaccesibles cabezas de las sierpes fluir con doliente desmayo, cuando Perseo dio un grito de júbilo, llevando la parte tercera de las hermanas cual destino fatal a Sérifos, de la mar bañada, y a sus habitantes. Y extinguió, sí, la estirpe divina de Forco, y amargo puso el banquete a Polidectes y la perene esclavitud de su madre y el forzado lecho matrimonial, cuando la cabeza de medusa de hermosas mejillas arrebató el hijo de Dánae que nació -decimos- del oro por sí mismo manante. Y cuando de estos trabajos sacó ella [Atenea] al hombre querido, la virgen diosa formó de las flautas [auloi] el omnísono canto que, con instrumentos, pudiera imitar el funeral gemido que de las temblorosas mandíbulas de Euríala brotara. Inventólo la diosa. Pero cuando lo inventó, para don a los hombres mortales, la llamó "melodía de las

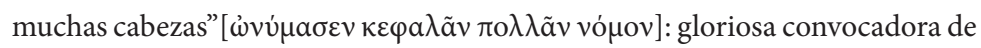
agones que a los pueblos atraen, melodía que pasa múltiples veces por el bronce delgado y las cañas (XII 1-25).

En esta versión del mito, Píndaro no solo atribuye a la diosa la invención del aulo, sino también la forma de tocarlo, que llamó "melodía de las muchas cabezas". El nomos Policéfalo fue una primitiva especie de diafonía musical, en la que los dos tubos del aulo emulaban el chirriante vocerío de las sierpes en la cabellera de la Gorgona Medusa. Mientras un tubo tocaba la melodía, el otro producía una especie de zumbido en calidad de bajo. 


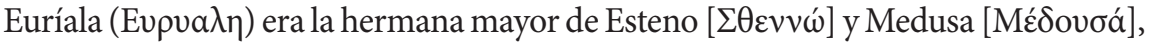

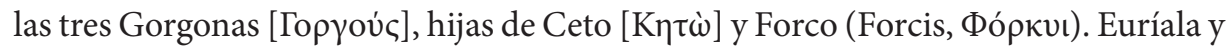
Esteno eran inmortales, mientras que Medusa, la menor, era mortal y fue decapitada por Perseo. En Teogonía, Hesíodo relata que:

A su vez Ceto tuvo con Forcis a las Grayas de bellas mejillas [...] y a las Gorgonas que viven al otro lado del ilustre Océano, en el confín del mundo hacia la noche, donde las Hespérides de aguda voz: Esteno, Euriale y la Medusa desventurada; ésta era mortal y las otras inmortales y exentas de vejez las dos. Con ella [Medusa] sola se acostó el de Azulada Cabellera [Poseidón] en un suave prado, entre primaverales flores. Y cuando Perseo le cercenó la cabeza, de dentro brotó el enorme Crisaor y el caballo Pegaso (270-71; 274-82).

Perseo, hijo de Dánae y Zeus, fue enviado por Polidectes en busca de las hijas de Forcis, y con la ayuda de Atenea y Hermes degolló a la Gorgona Medusa mientras dormía. En Escudo, Hesíodo describe cómo Perseo decapita al terrible monstruo:

Aquél [Perseo] volaba igual que el pensamiento; y por toda la espalda tenía la cabeza de un terrible monstruo, la Gorgona [...] Aquél, el Danaida Perseo, estaba en tensión como quien corre y es presa del miedo. Detrás de él, las Gorgonas horrendas e indecibles se precipitaban ansiosas de cogerle. A su marcha sobre el pálido acero, resonaba el escudo con gran estruendo, aguda y sonoramente. En su cintura, dos serpientes flotaban incurvando sus cabezas hacia delante; como dardos lanzaban su lengua las dos y daban furiosas dentelladas con los dientes, mirando de forma salvaje. Sobre las terribles cabezas de las Gorgonas se agitaba un terrible pánico $(223,229-237)$.

También Ovidio describe en Metamorfosis la decapitación de Medusa:

Narra el Agenórida que bajo el helado Atlas yacente hay un lugar, seguro por la defensa de su sólida mole; que de él en la avenida habitaron las gemelas hermanas Fórcides, que compartín de una sola luz el uso; [...] Que él, aun así, de la horrenda Medusa la figura había contemplado en el bronce repercutido del escudo que su izquierda llevaba, y mientras un grave sueño a sus culebras y a ella misma ocupaba le arrancó la cabeza de su cuello, y que, por sus plumas fugaz, Pegaso, y su hermano, de la sangre de su madre nacidos fueron (Iv 772-75,782-86).

Se dice que Atenea inventó el aulo para emular el chillido plañidero de las sierpes en la cabeza de Medusa. En la antigua Grecia, ciertos instrumentos producían sonidos infernales, sobre todo aquellos que fueron usados para provocar el delirio durante ceremonias orgiásticas; entre ellos el aulo, con su penetrante y lacerante chillido semejante al grito de la Gorgona (Vernant 75-84).

En otras interpretaciones sobre la duodécima Oda Pítica, se explica la posible causa de la invención del aulo, al relacionar el terrible lamento de las Gorgonas so- 
brevivientes, Euríala y Esteno, con el grito simultáneo de triunfo de Perseo. Al oír acercarse el torrente serpenteante de las Gorgonas, con su desconsolado sufrimiento, fuera de la caverna Atenea escuchaba el grito de triunfo que profería Perseo después de decapitar a Medusa.

Estos son los gritos sincrónicos que evoca el aulo con sus dos pipas tocadas simultáneamente. Esta dualidad sonora emerge de su doble origen, ya que la victoria se vuelve complemento de la derrota. Al momento del triunfo, cuando Atenea pronuncia a su preferido en la duodécima Oda de Píndaro por sus esfuerzos en el certamen Pítico, el aulo contrapone a la alegría alcanzada el desconsolado lamento de Euríale, la Gorgona mayor, caracterizada por sus sentimientos maternos hacia Medusa. Esta es la antífona lacerante del aulo, ambivalente entre la victoria y la derrota (Strauss 519-23).

La triple forma de la Gorgona no es primitiva, ya que el trío de hermanas es la multiplicación posterior de la Gorgona original, Medusa. Esto fue el resultado de una tendencia en la mitología por hacer de cada diosa una trinidad. En esencia, Medusa era solo una cabeza y nada más. Su poder inicia cuando su cabeza es cortada, y en ella reside el poder del mito (Harrison 187).

La imagen de la cabeza de Medusa representaba en la Grecia arcaica un artilugio que alejaba el mal, conocido como Gorgoneion [Гopүóveıov], especie de amuleto mágico apotropaico que inducía horror a quien se le mostraba. Por eso el nombre original

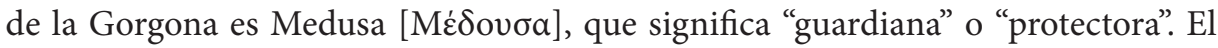
Gorgoneion se remonta más allá del siglo vir a. c., y hasta el siglo v a. c. se le representó como la cabeza de un horrendo monstruo. Posteriormente, comienza a representarse a la Gorgona en la mitología lírica como una bella doncella, pero a la vez terrorífica. Hesíodo menciona en Teogonía que Medusa tuvo relación con Poseidón, el de azulada cabellera. En la versión de Ovidio (Metamorfosis Iv 790-803), Medusa era una hermosa doncella sacerdotisa del templo de Minerva (Atenea). Al ser violada por el dios de los mares Neptuno (Poseidón), enfurecida y celosa Minerva transformó su hermoso cabello en chirriantes serpientes, ya que era el objeto de atracción de Neptuno.

En su recuento de auletas y citaristas, Plutarco atribuye el nomos Policéfalo al mítico auleta Olimpo de Misia. Basándose en el testimonio del poeta trágico Pratinas (s. v a.c.), señala sobre la ambigüedad de Olimpo, que va de la genealogía mítica a la personalidad histórica:

Después que hemos dado a conocer a la vez los antiguos nomos aulódicos y

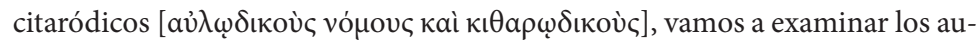
léticos. Se dice, en efecto, que Olimpo, mencionado anteriormente, que era un auleta de la escuela de Frigia, compuso un nomo[s] aulético en honor de Apolo,

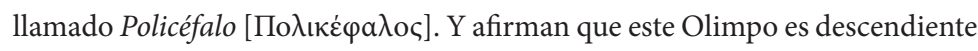
del primer Olimpo, discípulo de Marsias, y compositor de nomos en honor de los dioses; éste, en efecto, que fue favorito de Marsias y que aprendió de él el arte de tocar el aulo, introdujo en Grecia los nomos musicales, que todavía hoy usan los griegos en las fiestas de los dioses. Otros aseguran que el Nomo[s] 
Policéfalo es obra de Crates, que fue discípulo de Olimpo. Prátinas, en cambio, dice que este nomo[s] es de Olimpo, el Joven (De musica, 1133d3-e6 [c. 7]).

Plutarco también menciona que Olimpo compuso el nomos Policéfalo en honor de Apolo, y no de la diosa Atenea, como podría esperarse. En el escolio a la duodécima Oda Pítica de Píndaro, se afirma que Midas de Agrigento obtuvo la victoria en los juegos Píticos 24 y 25, esto es, en 494 y 490 a. C. y una victoria más en las Panateneas atenienses. ${ }^{11}$ Pero el nomos Policéfalo, al parecer, no está basado en ningún drama ritual a la diosa Atenea, como el nomos Píticos de Sacadas en el Septerion de Delfos. En su exposición sobre el carácter moral (éthos) de la música, Plutarco menciona como ejemplo el nomos de Atenea, que también atribuye a Olimpo, y posiblemente se trate del mismo nomos Policéfalo:

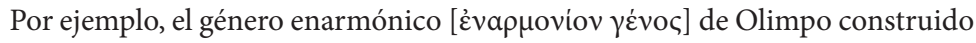

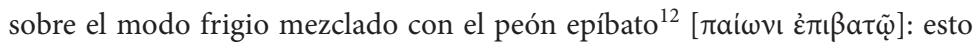

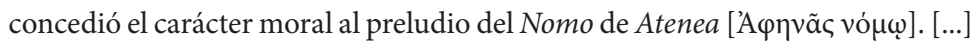
En efecto, la llamada harmonía en el Nomo de Atenea difiere mucho, en cuanto al carácter moral, de la anápeira (De musica 1143b2-c1 [c. 33]).

Este género enarmónico, que concede el carácter moral al preludio del nomos de Atenea, es descrito por Aristóxeno como "el tercero y más elevado [...], pues la percepción se acostumbra a él en último lugar y solo con un gran esfuerzo" (Harmónica I 19). Se trata de un género de difícil dominio, pues sus elementos micro-tonales exigen, tanto al intérprete como al oyente, una elevada competencia musical. Por ello, en la época de Aristóxeno, este género cayó en desuso. La estructura del tetracordio en este género consiste de dos diesis enarmónicas mínimas de cuartos de tono, denominada

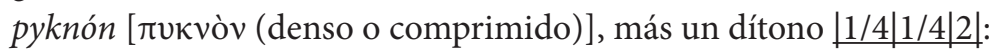

Los músicos, como dice Aristóxeno, creen que Olimpo es el inventor del género enarmónico, pues antes de él toda la música era diatónica o cromática. [...] En efecto, el pyknón enarmónico en el tetracordio medio, que ahora se usa, no parece ser de este compositor. Es fácil darse cuenta, si uno escucha a alguien que toca el aulo a la manera antigua, pues se pretende también que el semitono en el tetracordio medio sea simple. Así fue la introducción del género enarmónico. Más tarde, sin embargo, tanto en las composiciones frigias como en las lidias el semitono fue dividido. Olimpo, al parecer, enriqueció la música, al introducir algo que antes no existía y que era desconocido a sus predecesores, y llegó a ser el fundador de la noble música griega (Plutarco, De musica 1134f-1135c [c. 11]).

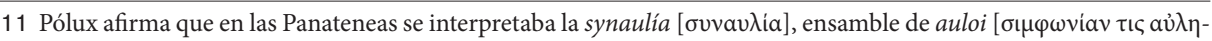
$\tau \tilde{\omega} v]$ (Onomasticon IV 83). Ateneo de Náucratis describe la synaulia como la conjunción del aulo y la lira sin canto (Deipnosophistaí xiv 9; Barker 274).

12 El peón epíbato es un pie poético compuesto de una sílaba larga y tres breves (Quintiliano, Sobre la música I 16). 
La extrema densidad del pyknón con sus cuartos de tono, y el subsiguiente salto del dítono en el tetracordio enarmónico, aunado a la gran capacidad tímbrica del aulo, permitieron a Midas de Agrigento representar la gran tensión entonativa requerida para emular el grito de Perseo y Euríala, o el chirriante vocerío de sierpes en la cabellera de Medusa, cristalizado en su nomos Policéfalo.

\section{Conclusiones}

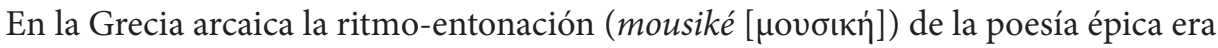
considerada de inspiración divina. Un don otorgado al aedo por las Musas, en contraste

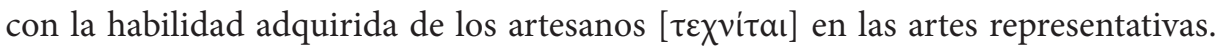
Además, la música era el único arte practicado por los dioses del olimpo, como Atenea, Apolo, Hermes o Dioniso. De ahí la creencia de su poder sobrenatural.

Esta idea también provenía del orfismo, la religión oculta de los griegos. Orfeo, su presunto fundador, fue un mítico cantor sin igual que poseía poderes mágicos. Con el poder de su canto y la melodía de su lira movía todas las cosas, y sometía a voluntad a bestias y creaturas. También fue un psychagogós [ $\psi v \chi \alpha \gamma \omega \gamma o ́ c]$-conductor de almas-, capaz de hipnotizar con su música a los mismos dioses subterráneos en su descenso al Hades, y así devolver a la vida a su amada Eurídice. De allí, su facultad

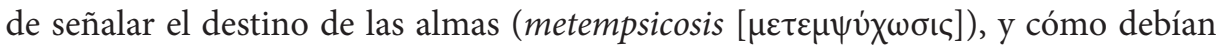
conducirse sus seguidores en este mundo [ßíoৎ о

Para la teoría ética del éthos, atribuida a Damon de Oda, el poder de influjo de la música era el vehículo primordial entre el mundo de los sonidos y el ético. Por ello, la música no era solo un placer ordinario de agradable combinación de sonidos y ritmos, como afirmarían después el epicúreo Filodemo de Gadara (s. I a.c.) y el escéptico Sexto Empírico (s. III d.c.), sino una fuerza excepcional psicagógica y ética. Un arte capaz de conducir y educar el alma humana.

Aristóteles, un seguidor de la teoría del éthos, atribuyó el poder de influjo de la música a su capacidad mimética. La imitación (mimesis $[\mu i \mu \eta \sigma \iota \varsigma]$ ) de la naturaleza como fin esencial del arte. Ciertamente, la música es capaz de imitar los movimientos del alma, expresando en sonidos de forma similar a las entonaciones verbales y gestuales del ser humano. De hecho, esta similitud entre lenguaje y música es el principio por el cual es posible imitar entonativamente los estados anímicos del ser humano, los movimientos de su alma y su relación con las cosas. ${ }^{13}$

Esta capacidad mimética de participación o presencia de ideas y emociones en los sonidos (metexis $[\mu \varepsilon \dot{\varepsilon} \theta \xi \iota \varsigma]$ ), fue el principio que auletas y citaristas utilizaron de manera intuitiva para representar entonativamente lo que el mito narraba, motiva-

13 La similitud entonativa entre lenguaje y música es de hecho la hipótesis fundamental en las teorías sobre el origen de la música desde la Ilustración (Condillac; Burnett ; Rousseau; Асафьев). 
dos por los certámenes musicales de los juegos Píticos en Delfos. En dicha imitación entonativa, el nomos aulético toma la forma y el contenido de la narración mítica, produciéndose la primera narración musical y, en consecuencia, la primera forma musical de la historia, fruto de la inspiración poiética del mito. Su forma es pues la cristalización musical del mito.

La gran capacidad del aulo para la expresión dramática y emocional, así como su amplio rango sonoro para producir diversos colores y su gran volumen, hicieron de este instrumento musical el medio ideal para la representación mimética en el nomos Píticos y Policéfalo. El nomos Píticos representaba la lucha del dios Apolo con el dragón Pitón en la fundación de Delfos. La versatilidad del aulo para expresar distintas emociones le permitieron a este género musical del nomos representar la violenta muerte del monstruo y la danza triunfal del dios Apolo.

El nomos Policéfalo, por su parte, representaba una diafonía de voces entre el grito triunfal de Perseo al decapitar a Medusa, y el lamento de la Gorgona Euríale, su hermana mayor. Esto fue posible gracias a los dos tubos del aulo tocados simultáneamente, con su capacidad tímbrica de emular el grito de Perseo y Euríala o el chirriante vocerío de sierpes en la cabellera de Medusa.

Estos nomoi fueron narraciones entonativas del mito. El primero basado en el programa de la representación mimética del relato mítico en el ritual délfico (Septerion). Es la cristalización musical del drama ritual, concebido de manera deliberada para reproducir entonativamente el mito. Inicialmente fue de tipo ritual, tal vez con música y danza, en una representación repetida del mito propio del culto. Posteriormente, se desarrolló en la dramatización escénica, dándole un orden y una forma de expresión artística que culmina en 574 a.c. con auleta Sácadas de Argos. Ochenta y cuatro años después, el auleta Midas de Agrigento realiza ya una libre recreación dramático-entonativa del mito de Atenea, Perseo y Medusa, al parecer sin mediación del rito, con su nomos Policéfalo de los juegos Píticos en 490 a. C.

\section{Referencias}

Anderson, W. D. “The Importance of Damonian Theory in Plato's Thought”. Transactions of the American Philological Association, Lxxxvi, 1955, pp.88-102.

---. Ethos and Education in Greek Music. The Evidence of Poetry and Philosophy. Harvard University Press, Cambridge, Massachusetts, 1968.

Aristóteles. Retórica. Traducción Q. Racionero. Madrid, Gredos, 1998.

---. Problemas. Traducción Ester Sánchez Millán. Madrid, Gredos, 2004.

Aristóxeno. Harmónica-Rítmica. Traducción de Francisco Pérez Cartagena. Madrid, Gredos, 2009, pp. 215-365.

Athenaeus [Ateneo]. The Deipnosophists or Banquet of the Learned of Athenaeus. Translated by C. D. Yonge, 3 Vol., London, Henry G. Bohn, York Street, Covent Garden, 1854. 
Асафьев, Борис. Музыкальная форма как процесс. Книга первая и вторая, Интонация. Ленинград, Музгиз, 1971.

Barker, Andrew, editor. Greek Musical Writings, 2 vols. Cambridge Readings in the Literature of Music. Cambridge, Cambridge University Press, 1984-89.

Bélis, Annie. "La phorbéia”. Bulletin de correspondance hellénique, n Cx, 1986, pp. 205-18. Burnett, James Lord Monboddo. On the origin and progress of language. Edinburgh, 1774.

Condillac, Étienne Bonnot de. Essai sur l'origine des connoissances humaines. Paris, 1746. ---. Das Marmor Parium. Berlin, Herausgegeben und Erklärt von Felix Jacoby, 1904.

Diodorus Siculus. Diodori Bibliotheca Historica, Vol 1-2. Immanel Bekker. Ludwig Dindorf. Friedrich Vogel. in aedibus B. G. Teubneri. Leipzig, 1888-1890.

Edmonds, John Maxwell, editor. Lyra Graeca. Being the remains of all the Greek Lyric Poets from Eumelus to Timotheus excepting Pindar, III vols. London, William Heinemann, 1922-27.

---. The Fragments of Attic Comedy, Volume II. E. J. Brill. Netherlands, Leiden, 1959.

Else, Gerald F. “'Imitation’ in the Fifth Century”. Classical Philology, n 53, 1958, pp. 73-90.

Estrabón. Geografía III. Libros viII-X. Traducción de Ma. Meana Cubero et al. Madrid, Gredos, 2008.

Fontenrose, Joseph. Python. Estudio del mito délfico y sus orígenes. Madrid, Sexto Piso, 2009.

García Gómez, Arturo. "Mousiké, el arte de la memoria (Mousiké, the art of memory)". Revista Cátedra de Artes. Revista de Artes Visuales, Música y Teatro, $\mathrm{n}^{\circ}$ 13, 2013, pp. 70-88.

Harrison, J. Ellen. Prolegomena to the Study of Greek Religion. Cambridge, Cambridge University Press, 1903.

Heracliti Ephesii Reliquiae. Recensuit I. Bywater, Oxonii, 1877.

Hesíodo. Obras y Fragmentos. Teogonía. Trabajos y días. Escudo. Fragmentos. Certamen. Madrid, Gredos, 2000.

Howard, Albert. "The Aủ入óৎ or Tibia”. Harvard Studies in Classical Philology, vol. 4, 1893, pp. 1-60.

Hygini [Gayo Julio Higinio]. The Myths of Hyginus, Translated by Mary Grant, Publications in Humanistic Studies, no. 34. Lawrence, University of Kansas Press, 1960.

Longo, Angela. "Sull'atribuzione della Crestomatia a Proclo Neoplatonico". SIFC, $\mathrm{n}^{\circ}$ 13, 1995, pp.110-14

Ovidio Nason, Publio. Metamorfosis. Libros I-v. Madrid, Gredos, 2008.

Panaiotidi, Elvira G. "The Myth of the Isomorphism”. International Review of the Aesthetics and Sociology of Music, no 38, 2007, pp. 133-142.

Paquette, M. Daniel. "Organologie de la Grèce Antique”. Revue de Musicologie, n², 1980, pp. 262-265.

Pausanias. Descripción de Grecia. Libros I-X. Introducción, traducción y notas de María Cruz Herrero Ingelmo. Madrid, Gredos, 1994. 
Photii [Photius, Constantinopolitan Patriarchae]. Opera Omnia. Bibliotheca sive Myrabiblon. Tomus secundus et tertius, Patrologiae. Parisis, Accurante J. P. Migne, 1861.

Pickard-Cambridge, Sir Arthur Wallace. Dithyramb Tragedy and Comedy. Oxford, Clarendon Press, 1962.

Píndaro. Odas y fragmentos. Olímpicas, Píticas, Nemeas, Ístmicas, Fragmentos. Introducción, traducción y notas de Alfonso Ortega. Madrid, Gredos, 1995.

Platón. Diálogos. viı Leyes (I-v). Madrid, Gredos, 1999.

---. Diálogos. vi Filebo, Timeo, Critias. Madrid, Gredos, 1997.

Plutarco. De defectu oraculum in: Plutarch's Morals, Why the Oracles cease. Vol. IV. Corrected and revised by William W. Goodwin, Ph. D. Boston, Little, Brown, and company, 1878, pp. 3-64.

---. Quaestiones Graecae in: Plutarch's Morals, The Greek Questions. Vol. II. Corrected and revised by William W. Goodwin, Ph. D., Boston, Little, Brown, and company, 1878, pp. 265-293.

---. De musica. Obras Morales y de Costumbres xiii, Sobre la música. Introducción, traducción y notas de José García López. Madrid, Gredos, 2004, pp. 7-140.

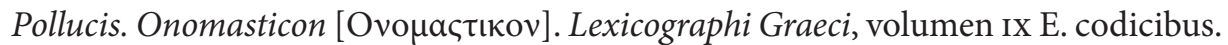
Fascivilus Prior Lib. I-v. Teubneri, Lipsiae, 1900.

Proclu. De Procli Chrestomathia Grammatica Quaestiones Selectae. F. Stein ed., Bonnae, 1907. Quintiliano, Arístides. Sobre la música. Introducción, traducción y notas de Luis Colomer y Begoña Gil. Madrid, Gredos, 1996.

Rousseau, Jean Jaques. "Essai sur lorigine des langues où il est parlé de la mélodie et de l'imitation musicale". Collection complète des cuvres de J. J. Rousseau, Citoyen de Genève. A Genève, Tome huitième, 1782, pp. 355-434.

Rutherford, Ian. "Apollo's Other Genre: Proclus on Nopo $\sigma$ and His Source”. Classical Philology, n 90, 1995, pp. 354-361.

Severyns, Albert. Recherches sur la Chrestomathie de Proclos. Première partie. Le Codex 239 de Photius; Tome I. Étude paléographique et critique; Tome II: Texte, traduction, commentaire, Paris, Droz, 1938.

Strauss Clay, Jenny. "Pindar's Twelfth Pythian: Reed and Bronze". The American Journal of Philology, $\mathrm{n}^{\circ} 113,1992$, pp. 519-525.

Suidae [Suda]. Lexicon. Graece et Latine. Halis et Brunsvigae, Tomus Prior, 1853.

Tatarkiewicz, Władysław. Historia de la estética. 1. La estética antigua. Madrid, Akal, 2011.

---. Historia de seis ideas. Arte, belleza, forma, creatividad, mímesis, experiencia estética. Madrid, Tecnos, 2008.

Vernant, Jean-Pierre. La muerte en los ojos. Figuras del otro en la antigua Grecia. Barcelona, Gedisa, 1986.

Recibido: 23 junio 2016

Aceptado: 9 marzo 2018 